\title{
ANÁLISE DO COMPORTAMENTO EMPREENDEDOR DOS ALUNOS DO 2 E 8 PERÍODOS DO CURSO DE ADMINISTRAÇÃO DA UNIVERSIDADE DO ESTADO DE MINAS GERAIS (UEMG) - FRUTAL
}

\section{doi> 10.33726/akdpapers2447-7656v9a62020p70-89}

\author{
BRANDÃO, Matheus Franck ${ }^{1}$ \\ SILVA, Josney Freitas ${ }^{2}$ - (D) https://orcid.org/0000-0002-9349-4497 \\ BUENO, Miriam Pinheiro ${ }^{3}$ \\ CALDEIRA, Carlos Alípio ${ }^{4}$ \\ NUNES, Ana Lúcia de Paula Ferreira ${ }^{5}$
}

\begin{abstract}
RESUMO: Este trabalho se constitui por meio da análise do comportamento empreendedor que se manifesta junto às turmas do $2^{\circ}$ e $8^{\circ}$ períodos do Curso de Administração, da Universidade do Estado de Minas Gerais (UEMG) - Unidade Frutal. A pesquisa foi conduzida pela metodologia de aplicação de um questionário realizado com o público-alvo do estudo, durante o mês de outubro de 2019, a partir de questões disponibilizadas na plataforma digital do GoogleForms. O objetivo foi o de verificar se os acadêmicos do curso de Administração da referida instituição de ensino compreendem o que, de fato, é empreendedorismo, bem como se conseguem assimilar características do comportamento empreendedor, visto que o empreendedorismo é uma disciplina muito importante no âmbito desta graduação. Ao final dos estudos, as conclusões indicaram que os alunos entrevistados demonstraram saber o que é o empreendedorismo. Além disso, os discentes já praticam os seus conhecimentos sobre o que é ser empreendedor, ou pelo menos, possuem grande interesse em empreender.
\end{abstract}

PALAVRAS-CHAVE: Universidade, Administração, empreendedorismo, alunos

ABSTRACT: This work is constituted through the analysis of the entrepreneurial behavior that manifests itself with the classes of the 2 nd and 8 th periods of the Administration Course, of the State University of Minas Gerais (UEMG) - Frutal Unit. The research was conducted using the methodology of applying a questionnaire conducted with the target audience of the study, during the month of October 2019, based on questions made available on the GoogleForms digital platform. The objective was to verify if the students of the Administration course of the referred educational institution understand what, in fact, is entrepreneurship, as well as if they are able to assimilate characteristics of entrepreneurial behavior, since entrepreneurship is a very important discipline within the scope of this University graduate. At the end of the studies, the conclusions indicated that the students interviewed demonstrated that they know what entrepreneurship is. In addition, students already practice their knowledge of what it means to be an entrepreneur, or at least have a great interest in entrepreneurship.

KEYWORDS: University, Administration, entrepreneurship, students

${ }^{1}$ Graduando em Administração pela Universidade do Estado de Minas Gerais - UEMG - Unidade Frutal / MG. E-mail: <matheusfranckbrandao@hotmail.com>.

${ }^{2}$ Doutor em Ensino de Ciências e Matemática. Mestre em Ensino de Ciências. Especialista em Gestão de Pequenas e Médias Empresas. Especialista em Gestão Empresarial Estratégica. Licenciado em Matemática e Pedagogia. Professor efetivo na Universidade do Estado de Minas Gerais - UEMG Unidade Frutal / MG. E-mail: < josney.silva@uemg.br>.

${ }^{3}$ Doutora em Engenharia Urbana e Mestre em Agronegócios. Professora efetiva na Universidade do Estado de Minas Gerais - UEMG - Unidade Frutal / MG. Docente do Mestrado Profissional PROFNIT Pós-Graduação em Propriedade Intelectual e Transferência de Tecnologia para a Inovação. E-mail: <miriam.bueno@uemg.br>.

${ }^{4}$ Mestre em Engenharia da Produção. Especialista em Administração Global e Marketing. Professor efetivo na Universidade do Estado de Minas Gerais - UEMG - Unidade Frutal / MG. E-mail: <carlos.caldeira@uemg.br>.

${ }^{5}$ Mestra em Educação e Especialista em Administração Escolar. Professora efetiva e Coordenadora do Curso de Administração da Universidade do Estado de Minas Gerais - UEMG - Unidade Frutal / MG. Email: <ana.nunes@uemg.br>. 


\section{INTRODUÇÃO}

Trata-se o presente artigo de um estudo que analisa o comportamento empreendedor manifesto ou latente, dos alunos do $2^{\circ}$ e do $8^{\circ}$ período do curso de Administração da Universidade do Estado de Minas Gerais (UEMG) Unidade Frutal. A investigação tem por objetivo, verificar o conhecimento que os graduandos detêm acerca do que é o empreendedorismo e suas características.

Para um estudo adequado, foram utilizados diferentes conceitos, definições e compreensões que envolvem o tema empreendedorismo, a fim de fundar o presente estudo em referenciais teóricos extremamente relevantes para a abordagem do processo empreendedor.

Por isso, as questões aqui presentes se relacionam com a origem do empreendedorismo, com conceitos e teorias que Ihe dizem respeito, bem como com sua importância para a sociedade moderna, em especial a acadêmicos do Curso de Administração, para, no decorrer do artigo, conectar a construção teórica realizada com o conhecimento dos alunos de Administração, da Universidade do Estado de Minas Gerais (UEMG) - Unidade Frutal, acerca do tema.

É neste rumo, portanto, que Dornelas (2008) afirma que empreendedor é aquele que detecta uma oportunidade e cria um negócio para capitalizar sobre ela, assumindo riscos calculados. Desse modo, vemos que em qualquer definição de empreendedorismo encontram-se, pelo menos, os seguintes aspectos: um empreendedor (i) tem iniciativa para criar um novo negócio e paixão pelo que faz; (ii) sabe utilizar os recursos disponíveis de forma criativa, transformando o ambiente social e econômico onde vive; (iii) aceita assumir os riscos calculados e a possibilidade de fracassar.

Nesse sentido, é que, para Longenecker, Moore e Petty (2004, p. 09), "um estereótipo comum do empreendedor enfatiza características como uma enorme necessidade de realização, uma disposição para assumir riscos moderados e uma forte autoconfiança". Ideário que se consolida, como o 
pensamento de Dolabela (2010), donde se verifica que "o empreendedor é alguém que sonha e busca transformar seu sonho em realidade".

Após a exposição desses conceitos, que são alguns dos que deram base ao foco do presente trabalho, é lançada a seguinte pergunta de pesquisa: "Os alunos do $2^{\circ}$ e do $8^{\circ}$ período do curso de Administração da Universidade do Estado de Minas Gerais (UEMG) - Unidade Frutal, assimilam características do comportamento empreendedor?".

Para responder a essa pergunta, além de ter sido efetuado um levantamento sobre a teoria empreendedora e as características do comportamento empreendedor, foi aplicado um questionário aos alunos dos períodos analisados, cujas perguntas e respostas serão expostas mais adiante. Antes disso, é válido demonstrar que essa pesquisa é importante, original e viável, de acordo com a classificação de Castro (1977). Isto é, um tema de pesquisa é considerado importante quando este está relacionado a algo que divida ou afete uma parcela considerável de um determinado grupo de pessoas (CASTRO, 1977). Sendo assim, a presente análise pode ser considerada importante, pois atinge especificamente o conhecimento dos alunos sobre um tema importante para o curso de Administração, dentro da Universidade do Estado de Minas Gerais (UEMG) - Unidade Frutal.

Ainda, um tema é considerado original, se os resultados tiverem capacidade de superar as expectativas (CASTRO, 1977). No que se refere ao tema, o deste artigo pode ser visto como original, pois até o presente momento não houve outros estudos dessa natureza na instituição de ensino, a partir do qual se analisa a cultura empreendedora dos alunos que estão no início e no final do curso.

Com relação à viabilidade, ela consiste na possibilidade de realização de pesquisa, levando em consideração as capacidades do pesquisador, os recursos financeiros, os prazos, as informações disponíveis, entre outros fatores. Dessa forma, a elaboração da pesquisa que resultou nas conclusões do presente artigo é plenamente viável, logo, possível. Igualmente, as informações foram localizadas facilmente, pois os livros e os alunos a serem pesquisados encontram-se na Universidade em questão, e também pelo fato de o pesquisador ser integrante do Curso de Administração, da Universidade 
do Estado de Minas Gerais (UEMG) - Unidade Frutal. Consequentemente, percebe-se que o presente estudo atendeu à classificação utilizada por Castro (1977), donde se pode dizer que os resultados obtidos são legítimos.

\section{ASPECTOS TEÓRICOS}

De acordo com Dornelas (2005, p. 29), a palavra "empreendedor" vem do termo francês entrepreneur, que significa dizer que uma determinada pessoa assume riscos e começa algo novo.

Por sua vez, a obra de Brito, Pereira e Linard (2013), considera que os primeiros indícios do surgimento de um entrepreneur surgem no século XVII, momento em que os empreendedores tinham um acordo contratual com o governo para realizar a produção de seus produtos, mediante a assunção de riscos para propor investimentos em algo que fosse novo.

Desde então, os conceitos de empreendedorismo foram evoluindo até os dias atuais. Por isso, é conveniente trazer o entendimento de Hisrich e Peter (2004, p. 29) com relação ao conceito do que seja o empreendedorismo. Assim, estes autores o definem como o "processo de criar algo diferente e com valor, dedicando o tempo e o esforço necessário, assumindo os riscos financeiros, psicológicos e sociais correspondentes e recebendo as consequentes recompensas da satisfação econômica e pessoal".

Nas palavras de Baggio e Baggio (2014, p. 26):

O empreendedorismo pode ser compreendido como a arte de fazer acontecer com criatividade e motivação. Consiste no prazer de realizar com sinergismo e inovação qualquer projeto pessoal ou organizacional, em desafio permanente às oportunidades e riscos. É assumir um comportamento proativo diante de questões que precisam ser resolvidas.

Formulando conceitos mais ousados, Schumpeter (1988) institui o empreendedorismo como uma "destruição criativa", por meio da qual produtos ou métodos de produção existentes são destruídos e substituídos por novos. 
Num mesmo sentido, Barreto (1998) diz que o "empreendedorismo é habilidade de criar e constituir algo a partir de muito pouco ou de quase nada".

Por essa razão, pode-se dizer que o comportamento empreendedor impulsiona o indivíduo e transforma contextos que resultam na destruição de velhos conceitos, pois alguma das habilidades do empreendedor é a de ver o mundo com novos olhos, com novos conceitos, com novas atitudes e propósitos. Nesse ponto de vista, um empreendedor é o reflexo da firmeza com que ele assume um comportamento proativo diante de questões que precisam ser resolvidas para o aproveitamento integral de suas potencialidades racionais e intuitivas, em atitude de abertura para novas experiências e novos paradigmas, que podem surgir de oportunidades a qualquer momento.

Uma vez detectada uma oportunidade, dá-se início a um processo empreendedor, cujas fases, segundo Hisrich e Peter (2004) são (i) identificação e avaliação da oportunidade; (ii) desenvolvimento do Plano de Negócios; (iii) determinação e captação dos recursos necessários; (iv) gerenciamento da organização criada.

A capacidade de elaboração de um "Plano de Negócios" (businessplan) é uma das características mais importantes para um empreendedor, visto que 0 Plano é, segundo Dornelas (2008, p. 84), "um documento usado para descrever um empreendimento e o modelo de negócios que sustenta a empresa", ou seja, é o businessplan que sustenta e direciona os objetivos do empreendedor.

Resumindo, um empreendedor é, acima de tudo, uma pessoa capaz de elaborar um plano com coragem e recursos suficientes para impulsioná-lo, a fim de materializar coisas novas, concretizar ideias e sonhos próprios e vivenciar características de personalidade e comportamento que são muito comuns nas pessoas, afinal, não são todas as pessoas que têm coragem de assumir riscos com financiamentos e riscos de não ter o produto do seu negócio aceito no mercado. Claro que existem vários motivos que dificultam a materialização do potencial empreendedor, dentre eles a ansiedade diante do desconhecido; percepção distorcida sobre o que é o mundo do empreendedorismo; interesses pessoais afetados e problemas de ajustamento, entre outros, segundo ensinamentos de Pinto (2007). 


\section{A IMPORTÂNCIA DO EMPREENDEDORISMO PARA OS ACADÊMICOS DE ADMINISTRAÇÃO}

Segundo Dornelas (2008), por meio de alguns pontos convergentes, o perfil de um empreendedor o torna, também, um administrador. Por isso, mesmo que diversos fatores possam dificultar a materialização do potencial empreendedor, conforme mencionado acima, o importante para esta pesquisa é identificar, sobretudo, se os acadêmicos do curso de Administração da Universidade do Estado de Minas Gerais - Frutal, têm conhecimento dos conceitos sobre o que é o empreendedorismo, bem como se eles estão aptos a assimilar algumas das características relacionadas ao comportamento empreendedor.

Isso é muito importante, pois, de acordo com a apresentação do curso de Administração feita no site da Universidade do Estado de Minas Gerais (UEMG) - Unidade Frutal ${ }^{6}$ :

O curso forma profissionais para atuar como empreendedores, administrando recursos financeiros, materiais e de pessoas. Oferece formação técnica e humana de profissionais em um contexto local e global e construção de métodos e instrumentos para uma administração sistemática e organizada.

Assim, entende-se que um dos objetivos gerais do Curso de Administração é o de fornecer aos alunos conhecimentos e habilidades que se relacionem com o empreendedorismo. Portanto, é vital que os acadêmicos de Administração desenvolvam e adotem comportamentos e atitudes adequadas ao escopo do empreendedorismo, o que, consequentemente, se refletirá na manifestação de seu perfil como administrador.

Segundo o Serviço Brasileiro de Apoio às Micro e Pequenas Empresas SEBRAE (2007), os empreendedores são reconhecidos como componentes essenciais para mobilizar capital, agregar valor aos recursos naturais, produzir bens e administrar os meios para administrar o comércio, o que demonstra que

\footnotetext{
${ }^{6}$ UEMG - Universidade do Estado de Minas Gerais - Unidade Frutal. Administração. Disponível em: http://www.uemg.br/graduacao/cursos2/course/administracao. Acesso em: 10 dez. 2019.
} 
a graduação universitária em foco e o empreendedorismo têm tudo a ver.

Em complemento a isso, de acordo com Longenecker, Moore e Petty (2004), os empreendedores são visto como heróis populares da moderna vida empresarial, uma vez que eles criam vagas de emprego, introduzem inovações e estimulam o crescimento econômico, o que reforça o caráter de essencialidade conferido ao curso de Administração, especialmente no desenvolvimento de empreendedores, pois é fato que os alunos que sairão formados por este Curso têm mais condições de desempenhar papeis fundamentais na idealização, coordenação e realização de projetos, serviços e negócios.

Conforme o GEM - Global Entrepreneurship Manegement (2018), no Brasil, a taxa de empreendedorismo estabelecido (TTE) - que é definida por indivíduos que administram e são proprietários de negócios já consolidados -, foi de $38 \%$, ou seja, em cada cinco brasileiros adultos, dois eram empreendedores. A partir dessa taxa, estima-se que, aproximadamente, 52 milhões de brasileiros, entre 18 e 64 anos $^{7}$, estavam liderando alguma atividade empreendedora, seja na criação e consolidação de um novo negócio, ou realizando esforços para a manutenção de negócios já estabelecidos.

Com os dados demonstram, o empreendedorismo está em alta entre os brasileiros. Sabendo disso, o Curso de Administração, de fato, é um meio eficaz de uma pessoa conseguir as ferramentas para se tornar um bom empreendedor, já que, com as técnicas aprendidas ao longo da graduação, o profissional obtém melhor conhecimento sobre as maneiras de conduzir uma empresa.

\footnotetext{
${ }^{7}$ Nas taxas calculadas pelo GEM são contados como empreendedores todos os indivíduos envolvidos com algum negócio em estágio nascente ou estabelecido, independentemente desse negócio ser a sua ocupação principal. Ou seja, se o indivíduo exercer qualquer outra atividade paralela, seja ela principal ou secundária, ele será contabilizado na taxa. Por esse motivo, o número total de empreendedores estimado pelo GEM é sensivelmente maior do que o número apresentado pela PNAD (Pesquisa Nacional por Amostra de Domicílio), que contabiliza como "empregadores" ou "por conta-própria" (conceitos que se aproximam do "empreendedor GEM"), apenas os indivíduos que têm essa atividade como ocupação principal.
} 


\section{METODOLOGIA DE PESQUISA}

Antes da exposição da pesquisa deste trabalho, é importante observar que há diversas classificações quanto aos tipos de pesquisa que podem ser realizadas. Neste sentido, individualmente, cada uma conta com um conjunto de características, e cada tipo, ao seu modo, delineia as técnicas empreendidas na coleta e análise de dados durante a realização de estudos como o nosso. Portanto, em conjunto, elas formam o ambiente da metodologia da pesquisa.

Conforme Cervo, Bervian e Silva (2007 p. 27), "entende-se por método o conjunto de processos empregados na investigação e na demonstração da verdade". Para completar tal afirmação, Zanella (2007) diz que esse conjunto de processos é necessário para alcançar os fins de um estudo.

\section{a. Quanto aos fins e aos meios de pesquisa}

Segundo Vergara (2009), a pesquisa científica pode ser classificada de acordo com dois critérios básicos: quanto aos fins e quanto aos meios. Quanto aos fins, a pesquisa pode ser exploratória, descritiva, explicativa, metodológica, aplicada, intervencionista. No que se refere aos meios, ela pode ser de campo, de laboratório, telematizada, documental, bibliográfica, experimental, ex-postfacto, participante, pesquisa-ação e estudo de caso.

Quanto ao fim principal, este estudo possui caráter descritivo. Nas palavras de Triviños (1987, p. 110), "o estudo descritivo pretende descrever 'com exatidão' os fatos e fenômenos de determinada realidade", de modo que o estudo descritivo é utilizado quando a intenção do pesquisador é conhecer determinado público e suas características, com a intenção de gerar soluções para determinado problema que um público específico teria sob a perspectiva do estudo realizado.

Quanto aos meios, tais como expostos por Vergara (2009, p. 43), esta pesquisa apresenta características de uma pesquisa de campo, pois ela é "[...] a investigação empírica realizada no local onde ocorre ou ocorreu um 
fenômeno ou que dispõe de elementos para explicá-lo". E, para atingirmos este fim, podemos utilizar "entrevistas, aplicação de questionários, testes e observação participante ou não".

\section{b. Quanto às técnicas de coleta e análise de dados}

Primeiramente, um estudo deve ser caracterizado segundo suas variáveis, que podem ser qualitativas ou quantitativas (VERGARA, 2009).

Neste sentido, temos que esta pesquisa apresenta caráter qualitativo, pois, segundo Triviños (1987), a abordagem de cunho qualitativo trabalha os dados buscando seu significado, tendo como base a percepção do fenômeno dentro do seu contexto. $O$ uso da descrição qualitativa procura captar não só a aparência do fenômeno, como também suas essências, almejando explicar sua origem, relações e mudanças, e tentando intuir as consequências.

Para Gil (1999), o uso dessa abordagem propicia o aprofundamento da investigação das questões relacionadas ao fenômeno em estudo e das suas relações, mediante a máxima valorização do contato direto com a situação estudada, buscando-se o que era comum, mas permanecendo, entretanto, aberta para perceber a individualidade e os significados múltiplos.

Em segundo lugar, Lakatos e Marconi (2001) informam que as técnicas de coleta de dados são um conjunto de regras ou processos utilizados por uma ciência, ou seja, correspondem à parte prática da coleta de dados. Vale lembrar que, durante a coleta de dados, diferentes técnicas podem ser empregadas, sendo a mais utilizada delas, a entrevista, combinada ou não com o questionário, com a observação e com a pesquisa documental.

No presente case, a técnica de coleta de dados utilizada foi a da aplicação de questionário. As questões foram disponibilizadas ao público-alvo dos estudos na plataforma do GoogleForms, as quais foram respondidas por 76 alunos da Universidade.

De acordo com Cervo, Bervian e Silva (2002), um questionário é um meio de obter respostas às questões por uma fórmula que o próprio informante preenche e consiste numa série ordenada de perguntas, respondidas sem a presença do pesquisador. 
As vantagens do emprego dessa técnica de realização de pesquisa, é que, em primeiro lugar, a Universidade dispôs de tablets para que o público estudado respondesse às perguntas, o que instrumentalizou este estudo. Além disso, o questionário, da maneira em que foi feito, permitiu alcançar um maior número de pessoas. Nisto, se demonstrou ser a técnica mais econômica, uma vez que possibilitou a padronização das questões obtidas, e viabilizou uma interpretação mais uniforme dos dados obtidos entre os respondentes, o que, consequentemente, facilitou a compilação das respostas escolhidas, assegurando $o$ anonimato ao interrogado.

De modo geral, a metodologia adotada se baseia em pesquisa descritiva, que tem como objetivo básico o de descrever as características de populações e de fenômenos que, no presente caso, é o de encontrar características que relacionam os alunos do Curso de Bacharelado em Administração, da Universidade do Estado de Minas Gerais (UEMG), Unidade Frutal, com o perfil do empreendedorismo, por meio de levantamento de dados para descrever essas características, sendo que o questionário foi 0 instrumento padronizado de coleta dos dados, conformando um conjunto de procedimentos que conduziram 0 projeto aos resultados de natureza qualitativa.

\section{PESQUISA REALIZADA COM OS ACADÊMICOS DA UNIVERSIDADE: ANÁLISE DAS RESPOSTAS OBTIDAS POR MEIO DE QUESTIONÁRIO}

Na plataforma GoogleForms foram disponibilizadas um total de treze perguntas a serem respondidas pelos alunos dos $2^{\circ}$ e $8^{\circ}$ períodos do Curso de Administração da UEMG - Unidade Frutal, em turmas do período matutino e noturno. As questões tinham por objetivo, em primeiro lugar, reunir os dados gerais dos entrevistados, para depois coletar as perspectivas pessoais dos alunos sobre o que é o empreendedorismo; quais são suas características; bem como para captar como esses alunos se relacionam com a disciplina.

Abaixo, a descrição das perguntas feitas aos acadêmicos e as respostas obtidas: 


\section{a. Pergunta: Você estuda em qual período?}

No total, foram 76 entrevistados. $56,6 \%$ dos entrevistados são estudantes do $2 \%$ período, enquanto que $43,4 \%$ dos entrevistados estudam no 8o período.

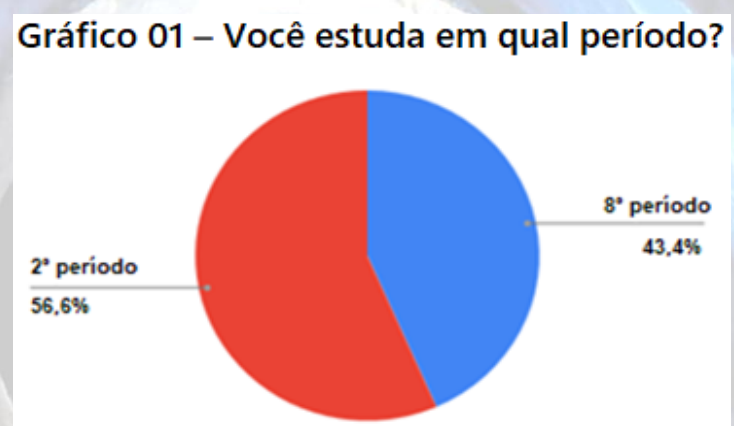

Fonte: Elaborado pelos autores (2019)

\section{b. Pergunta: Você estuda em qual turno?}

A maioria representa os alunos do ciclo noturno, com uma porcentagem de $52,6 \%$; e $47,4 \%$ referente aos alunos do turno matutino.

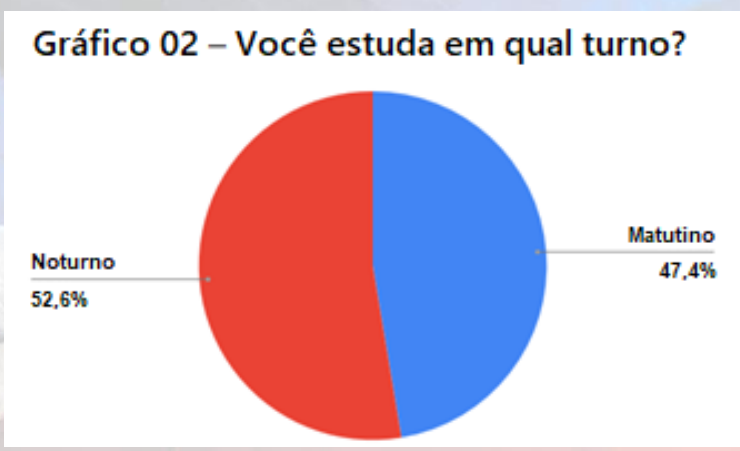

Fonte: Elaborado pelos autores (2019)

\section{c. Pergunta: Você se identifica com qual gênero?}

Entre os acadêmicos que responderam ao questionário, 29 se identificam com o gênero masculino e 47 estudantes se identificam com 0 gênero feminino. As mulheres deram a maioria das respostas da pesquisa.

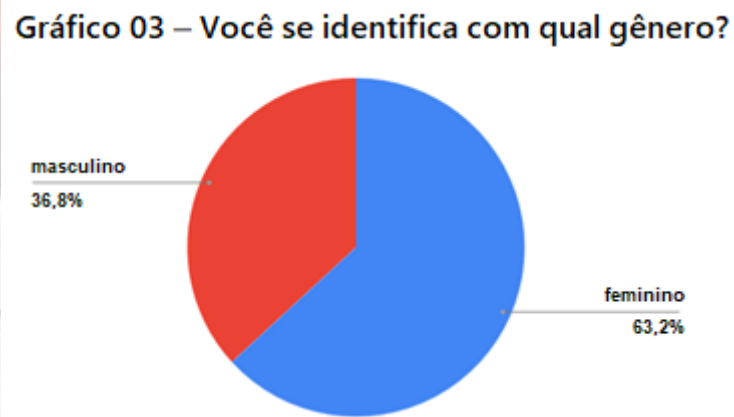

Fonte: Elaborado pelos autores (2019) 


\section{d. Pergunta: Qual a sua idade?}

Com relação às idades dos acadêmicos de Administração entrevistados, a faixa etária de 19 anos foi a mais recorrente. Convém informar, que o questionário obteve respostas de pessoas com idade mínima de 18 anos e idade máxima de 46 anos.

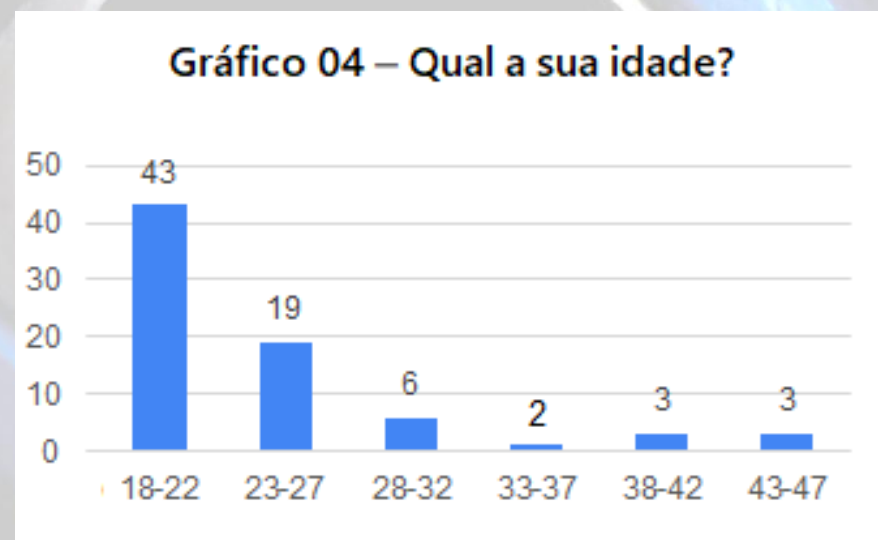

Fonte: Elaborado pelos autores (2019)

e. Pergunta: Você trabalha com vínculo empregatício, de maneira autônoma ou não trabalha?

Quando perguntados, 22 alunos responderam que trabalham de maneira autônoma, sendo 14 acadêmicos do $2^{\circ}$ período e 08 do $8^{\circ}$ período; 51 alunos responderam que possuem vínculo empregatício, sendo 29 alunos do $2^{\circ}$ período e 22 do 8o período; 02 pessoas não trabalham, nem com vínculo e nem de maneira autônoma, sendo essas duas pessoas do 8o período; e 01 pessoa, também do $8^{\circ}$ período, respondeu que trabalha de forma diversa das que foram perguntadas.

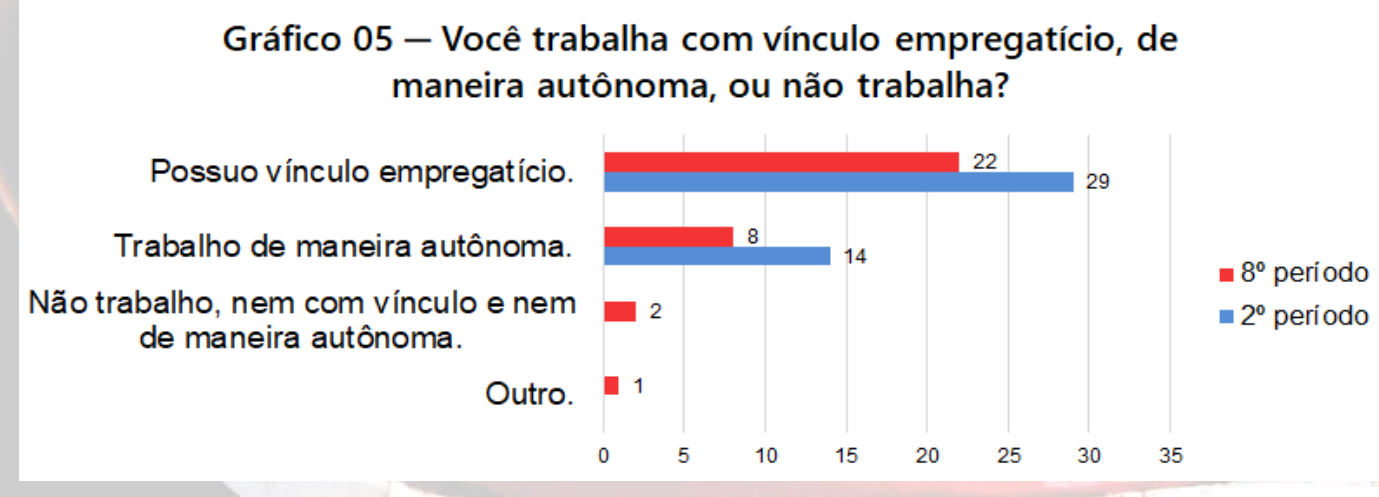

Fonte: Elaborado pelos autores (2019) 
f. Pergunta: Você acredita que a faculdade de Administração é importante para o empreendedorismo?

Quando perguntados, todos os alunos entrevistados consideraram a faculdade de Administração importante para o empreendedorismo.

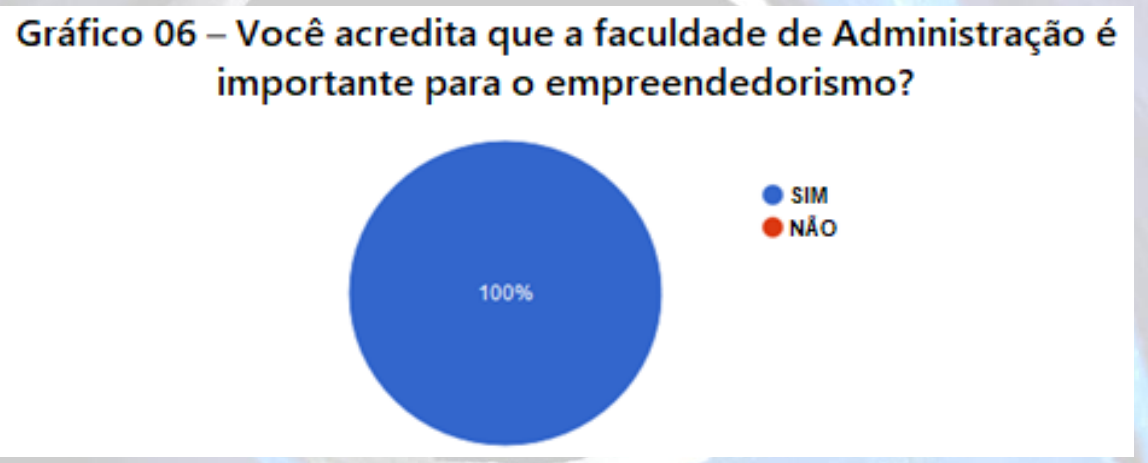

Fonte: Elaborado pelos autores (2019)

\section{g. Pergunta: Você entrou na faculdade de Administração para aprimorar o seu lado empreendedor?}

Entre os entrevistados do 2 período, 32 alunos responderam que entraram no curso de Administração, já com o objetivo de aprimorar os seus perfis empreendedores; e apenas 11 alunos responderam que não. Com

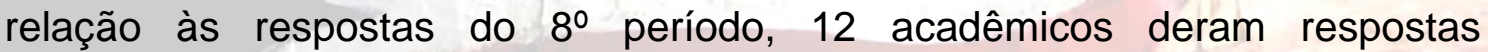
afirmativas para a pergunta, enquanto que 21 alunos informaram que não entraram para a Universidade com esse objetivo.

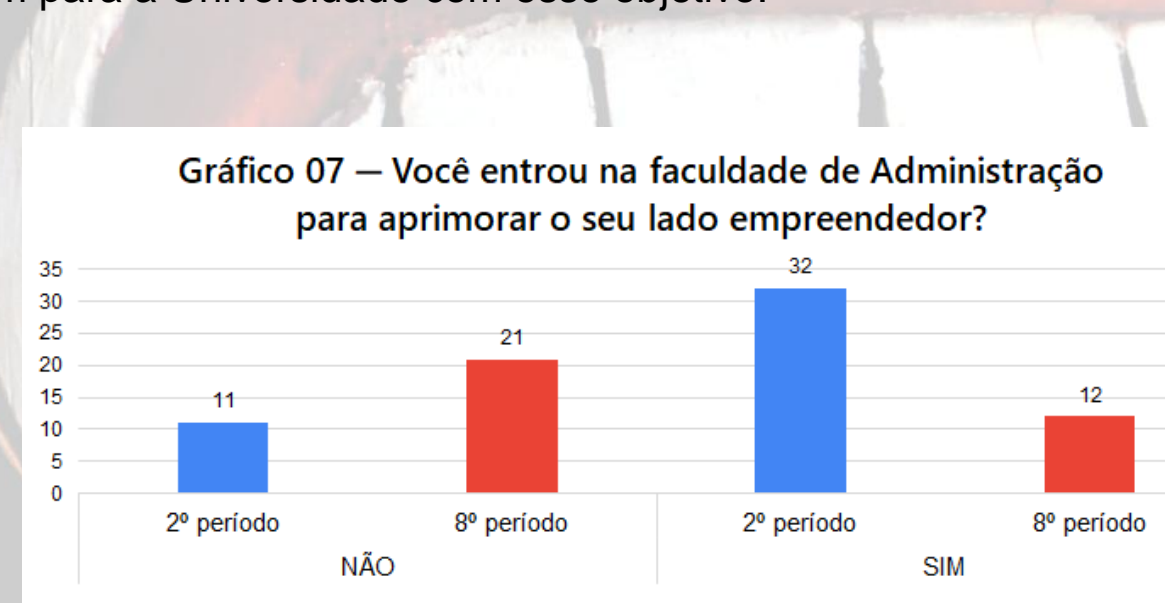

Fonte: Elaborado pelos autores (2019) 


\section{h. Pergunta: Você saberia conceituar o que é empreendedorismo?}

A maioria dos entrevistados respondeu que saberia conceituar o que é empreendedorismo. Contudo, apenas 06 alunos, do $2^{\circ}$ período, responderam que não saberiam atribuir um conceito à palavra. Todos os alunos do $8^{\circ}$ período informaram que saberiam conceituar empreendedorismo.

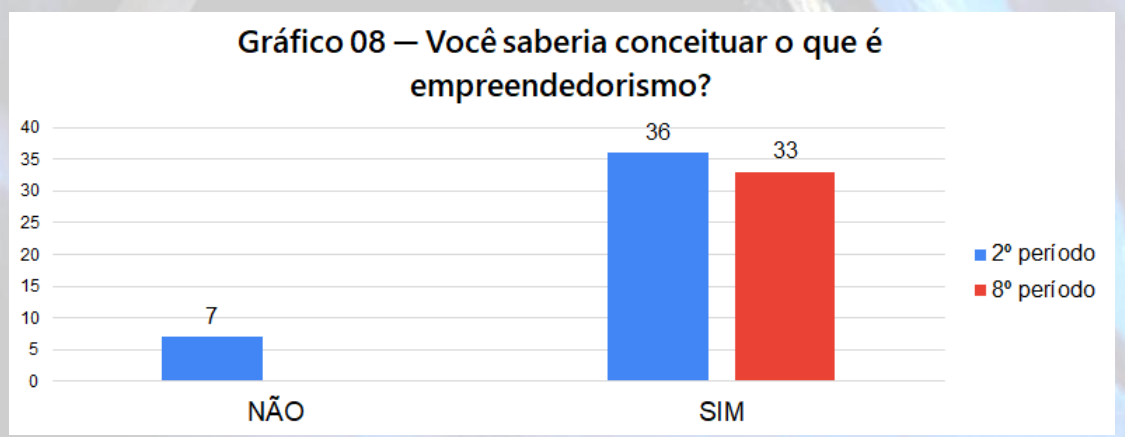

Fonte: Elaborado pelos autores (2019)

i. Pergunta: Para José Carlos de Assis Dornelas, "um empreendedor é aquele que detecta uma oportunidade e cria um negócio para capitalizar sobre ela, assumindo riscos calculados". Você concorda com essa definição?

Para complementar a pergunta feita sobre se os alunos conseguiriam conceituar o empreendedorismo, uma questão teórica foi formulada, com o intuito de detectar o quão próximo do conceito de empreendedorismo os alunos estariam. A proposição foi feita com base nos entendimentos de Dornelas (2008), no caput do item $\mathbf{i}$, e os alunos tiveram que responder se concordam com isso, ou não.

Um total de 41 alunos do $2^{\circ}$ período concordaram com o conceito de Dornelas, enquanto 02 alunos discordaram. Já, sobre os alunos do $8^{\circ}$ período, 29 alunos concordaram com o conceito de Dornelas, embora 04 acadêmicos tenham discordado.

Gráfico 09 - Para José Carlos de Assis Dornelas, "um empreendedor é aquele que detecta uma oportunidade e cria um negócio para capitalizar sobre ela, assumindo riscos calculados". Você concorda com essa definição?
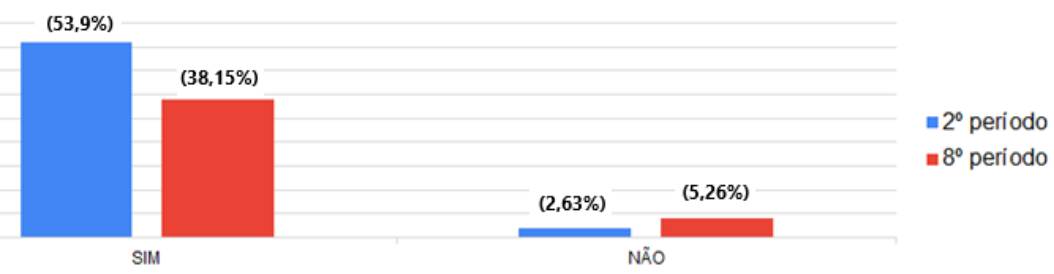

Fonte: Elaborado pelos autores (2019) 
j. Pergunta: Em sua opinião, a frase "os empreendedores são como lobos solitários que não conseguem trabalhar em equipe", é uma verdade ou um mito?

Na sequência, foi elaborada uma pergunta, também com base na teoria de Dornelas (2008), para fazer contraste com a questão anteriormente feita, pois em sua obra, após dar definição ao que é o empreendedorismo, Dornelas diz que seria um mito considerar os empreendedores como "lobos solitários que não conseguem trabalhar em equipe". Isso seria uma característica negativa a um empreendedor.

Desse modo, foi perguntado aos alunos se eles consideram essa afirmação um mito ou uma verdade, com o objetivo de analisar se os alunos seriam coerentes ou não com as respostas anteriores.

Assim, $86 \%$ dos alunos do $2^{\circ}$ período e $87,9 \%$ dos alunos do $8^{\circ}$ período responderam que consideram isso um mito. De fato, a resposta esperada seria a de que a maioria dos alunos considerasse essa afirmação um mito. No entanto, $14 \%$ dos entrevistados do $2^{\circ}$ período, com $12,1 \%$ do $8^{\circ}$ período, consideram isso como uma verdade.

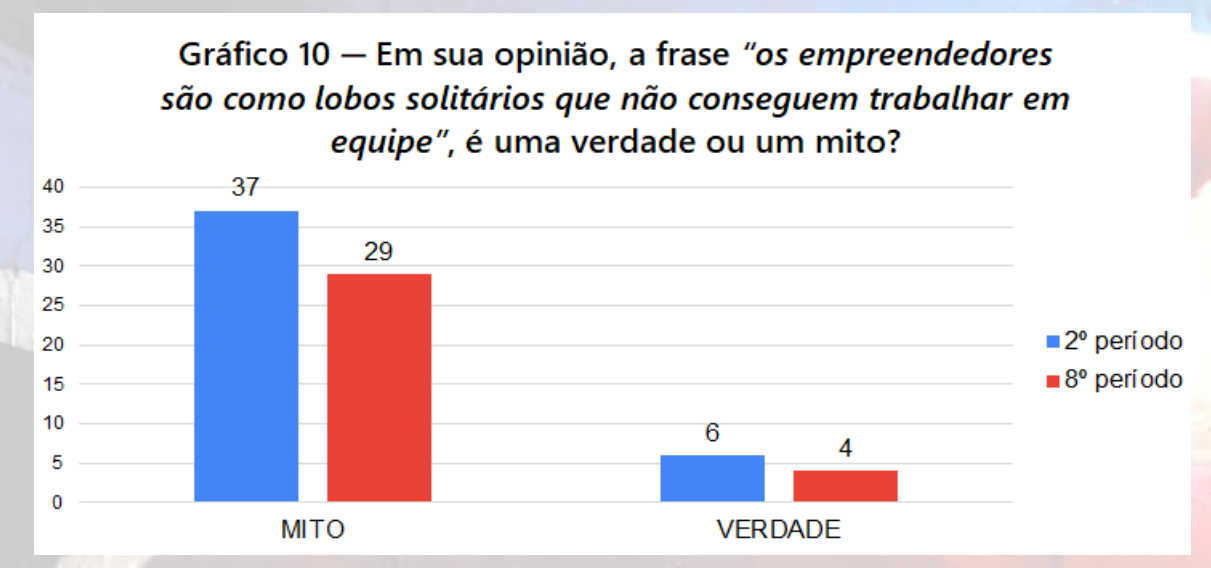

Fonte: Elaborado pelos autores (2019)

k. Pergunta: Você tem planos de abrir o seu próprio negócio ou expandir o negócio que você já possui?

Para compreender melhor como esses alunos entrevistados se relacionam com o empreendedorismo, foi perguntado se eles têm planos de abrir o próprio negócio ou planos de expandir o negócio que já possuem.

Dos entrevistados, 34 alunos responderam que sim, e que têm planos a serem colocados em prática; 21 alunos são do $2^{\circ}$ período e 13 são do $8^{\circ}$ período. Um total de 26 alunos responderam que pensam em abrir negócios próprios ou expandir os negócios que já possuem, mas que não desenvolveram planos a serem colocados em prática; sendo 16 alunos do $2^{\circ}$ período que responderam nesse sentido e 10 acadêmicos do 8o período.

Por fim, 16 alunos responderam que não possuem planos para abrir o próprio negócio e nem para expandir os negócios que já possuem, sendo que 
desses entrevistados, 06 alunos são do $2^{\circ}$ e 10 são do $8^{\circ}$ período.

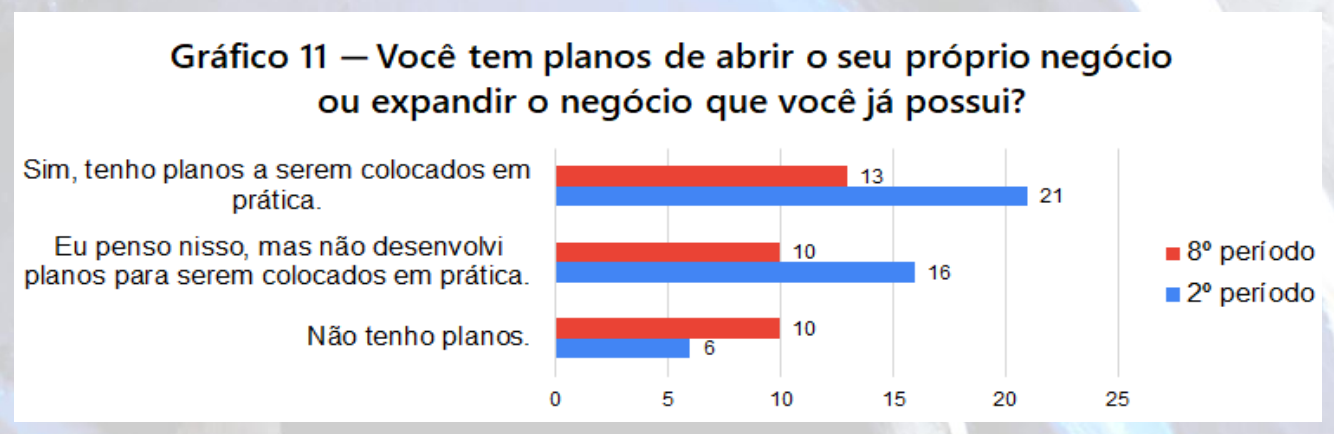

Fonte: Elaborado pelos autores (2019)

\section{Pergunta: Para abrir um negócio ou expandir um negócio, o que você considera mais importante?}

Também com o objetivo de captar o espírito empreendedor dos alunos entrevistados, foi perguntado o que eles acham mais importante quando da abertura ou expansão de um negócio. Isso, de acordo com as características que Dornelas (2008) atribui à um empreendedor, quais sejam: (i) ter iniciativa para criar um novo negócio e ter paixão pelo que faz; (ii) saber utilizar os recursos disponíveis de forma criativa; (iii) aceitar assumir os riscos calculados e a possibilidade de fracasso; (iv) importante considerar todas as hipóteses; ou (v) nenhuma dessas hipóteses.

A maioria dos alunos, tanto do $2^{\circ}$ quanto do $8^{\circ}$ período, respondeu que todos esses elementos são importantes. A segunda resposta mais escolhida pelos alunos dos dois períodos avaliados, é que o mais importante é saber utilizar os recursos disponíveis de forma criativa. Em terceiro lugar, para os alunos do $2^{\circ}$ período, o mais importante é assumir os riscos calculados e a possibilidade de fracasso, enquanto para o $8^{\circ}$ período, a terceira característica mais importante para abrir ou expandir um negócio é ter iniciativa para criar um novo negócio e ter paixão pelo que faz. Apenas 01 aluno, integrante do $8^{\circ}$ período, respondeu que nenhuma dessas características seria importante.

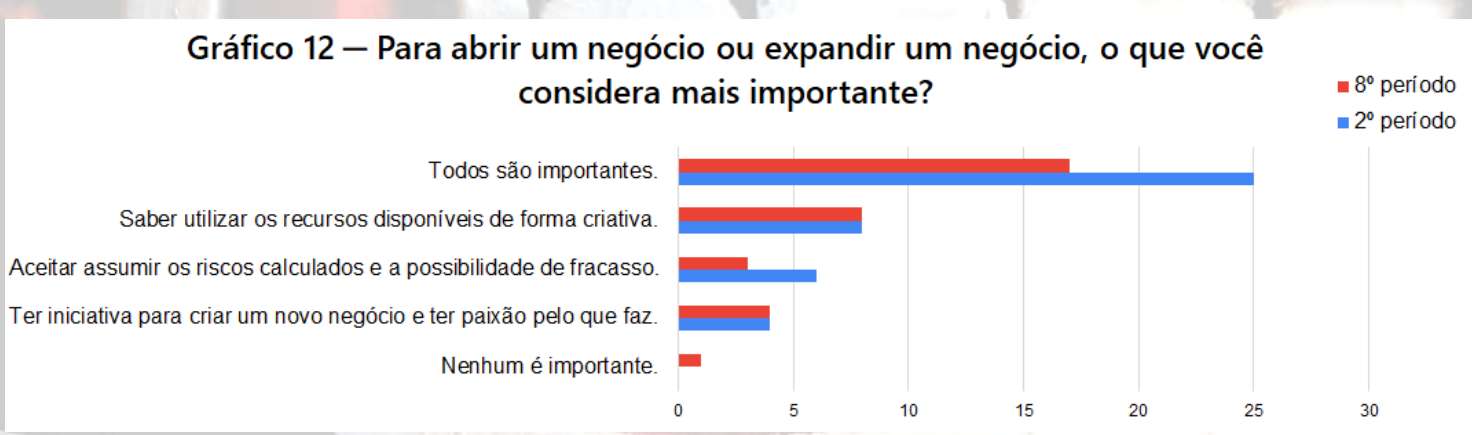

Fonte: Elaborado pelos autores (2019) 


\section{m. Pergunta: Com quais dessas características que você se identifica?}

Por fim, foram colocadas algumas características ligadas ao perfil empreendedor para que os alunos pudessem selecionar com quais delas eles se identificavam, objetivando ver qual a característica mais marcante entre as turmas. As opções eram: (i) "me considero visionário"; (ii) "sei tomar decisões"; (iii) "sei fazer a diferença"; (iv) "sou determinado e dinâmico"; e (v) "sou dedicado"; e os alunos poderiam escolher mais de uma opção com que eles se identificassem.

Vejamos a tabela com os resultados:

Tabela 1 - Com quais dessas características que você se identifica?

\begin{tabular}{|c|c|c|c|}
\hline CARACTERISTICAS & $\begin{array}{l}\text { 20 } \\
\text { PERÍODO }\end{array}$ & $\begin{array}{c}\text { 80 } \\
\text { PERÍODO }\end{array}$ & $\begin{array}{l}\text { TOTAL } \\
\text { GERAL }\end{array}$ \\
\hline Me considero visionário (a). & 2 & 1 & 3 \\
\hline $\begin{array}{l}\text { Me considero visionário (a)., Sei tomar decisões., Sei fazer a diferença., Sou } \\
\text { determinado (a) e dinâmico (a)., Sou dedicado }\end{array}$ & 4 & 2 & 6 \\
\hline $\begin{array}{l}\text { Me considero visionário (a)., Sei tomar decisões., Sou determinado (a) e } \\
\text { dinâmico (a). }\end{array}$ & 1 & & 1 \\
\hline Me considero visionário (a)., Sou determinado (a) e dinâmico (a). & 2 & & 2 \\
\hline $\begin{array}{l}\text { Me considero visionário (a)., Sou determinado (a) e dinâmico (a)., Sou } \\
\text { dedicado }\end{array}$ & & 1 & 1 \\
\hline Sei fazer a diferença. & 3 & 1 & 4 \\
\hline Sei fazer a diferença., Sou determinado (a) e dinâmico (a)., Sou dedicado & 1 & 3 & 4 \\
\hline Sei tomar decisões. & 4 & 2 & 6 \\
\hline Sei tomar decisões., Sei fazer a diferença., Sou dedicado & & 1 & 1 \\
\hline $\begin{array}{l}\text { Sei tomar decisões., Sei fazer a diferença., Sou determinado (a) e dinâmico } \\
\text { (a)., Sou dedicado }\end{array}$ & 3 & 2 & 5 \\
\hline Sei tomar decisões., Sou dedicado & 2 & 1 & 3 \\
\hline Sei tomar decisões., Sou determinado (a) e dinâmico (a). & 3 & 2 & 5 \\
\hline Sei tomar decisões., Sou determinado (a) e dinâmico (a)., Sou dedicado & 1 & 3 & 4 \\
\hline Sou dedicado & 3 & 2 & 5 \\
\hline Sou determinado (a) e dinâmico (a). & 13 & 9 & 22 \\
\hline Sou determinado (a) e dinâmico (a)., Sou dedicado & 1 & 3 & 4 \\
\hline Total Geral & 43 & 33 & 76 \\
\hline
\end{tabular}

Fonte: Elaborado pelos autores (2019)

De acordo com a tabela acima, a característica predominante, tanto dos acadêmicos do $2^{\circ}$ período quanto do $8^{\circ}$ período, de acordo com eles mesmos, é ser determinado e dinâmico. 


\section{CONSIDERAÇÕES FINAIS}

Os estudos realizados com as turmas do $2^{\circ}$ e $8^{\circ}$ períodos do Curso de Bacharelado em Administração, da Universidade do Estado de Minas Gerais (UEMG) - Unidade Frutal, resultaram em diversas observações relevantes e positivas quanto às perspectivas dos alunos sobre o empreendedorismo.

De acordo com o Gráfico 05, observa-se que entre os entrevistados, tem-se um número razoável de trabalhadores autônomos, em que 22 alunos, no total, são autônomos, sendo a maioria deles pertencentes ao $2^{\circ}$ período.

Conforme o Gráfico 06, um aspecto encontrado nas questões feitas, é que todos os 76 alunos entrevistados concordaram que a graduação em Administração é importante para os assuntos que envolvem 0 empreendedorismo, o que ilustra bem o subcapítulo 2.1. desse artigo, " $A$ importância do empreendedorismo para os acadêmicos de Administração", que expõe motivos pelos quais a disciplina que trata do empreendedorismo é muito relevante para a formação dos acadêmicos de Administração.

Quando perguntados se entraram para a Universidade com o objetivo de aprimorar os seus lados empreendedores, a maioria dos alunos do $2^{\circ}$ período informou que sim, que eles entraram para o curso de Administração com esse objetivo. Já, a maioria dos alunos do 8 o período, informou que não entraram para o curso com a finalidade de aprimorar seus perfis empreendedores. É o que demonstra o Gráfico 07.

Num dado momento, os alunos foram questionados se saberiam conceituar empreendedorismo. Todos os alunos do $8^{\circ}$ período responderam que saberiam atribuir um conceito à palavra. Com relação aos alunos do $2^{\circ}$ período, a grande maioria diz saber conceituar o que é empreendedorismo (Gráfico 08).

Quando questionados se concordavam com 0 conceito de empreendedorismo atribuído a Dornelas (2008), a maioria dos alunos, tanto do $2^{\circ}$ quanto do $8^{\circ}$ período, responderam que concordam. O que quer dizer que grande parte dos acadêmicos entrevistados assimilam bem o conceito do que é ser um empreendedor (Gráficos 09).

Ainda, conforme mencionado, os alunos foram perguntados se 
consideram os empreendedores como "lobos solitários que não conseguem trabalhar em equipe" e, de acordo com o Gráfico 10, a maioria dos alunos consideraram isso um mito. Esta era mesmo a resposta esperada pela equipe de pesquisa, pois não saber trabalhar em equipe é um fator que Dornelas (2008) aponta como sendo negativo para o perfil empreendedor.

No geral, os acadêmicos demonstraram ter muito interesse em abrir o próprio negócio ou expandir o negócio que já têm. Com isso, é possível concluir que os alunos do $2^{\circ}$ e do $8^{\circ}$ períodos de Administração possuem vontade de alavancar a área do empreendedorismo (Gráfico 11), e também vocação, porque, conforme as respostas obtidas, a maioria desses alunos concorda que ter iniciativa para criar um novo negócio e ter paixão pelo que faz, saber utilizar os recursos disponíveis de forma criativa, e aceitar assumir os riscos calculados e a possibilidade de fracasso, são fatores importantes para a abertura e expansão de negócios (Gráficos 12).

Por fim, após a análise das respostas obtidas, podemos concluir que a resposta para a pergunta de pesquisa "os alunos do $2^{\circ}$ e do $8^{\circ}$ períodos do Curso de Administração da Universidade do Estado de Minas Gerais (UEMG) Unidade Frutal, assimilam características do comportamento empreendedor?", é que sim, que a maioria dos alunos do $2^{\circ}$ e do $8^{\circ}$ períodos do Curso de Administração, da Universidade do Estado de Minas Gerais (UEMG) - Unidade Frutal, assimilam características do comportamento empreendedor.

Importante ressaltar que, mesmo que os alunos do $2^{\circ}$ período ainda não tivessem estudado formalmente as disciplinas relacionadas diretamente ao empreendedorismo, eles demonstraram ter conhecimento empírico sobre o tema. Dessa forma, pode-se dizer que a Universidade está formando boas turmas de empreendedores, e que o empreendedorismo está se expandindo entre os acadêmicos de Administração, uma vez que os alunos do $2^{\circ}$ período demonstram envolvimento com o assunto empreendedorismo.

Em suma, vê-se que é papel da Universidade continuar a estimular esses alunos, para que eles se concretizem como parte do futuro do empreendedorismo e, com isso, ajudem no crescimento econômico, na melhora da condição de vida das pessoas, na geração de mais empregos e no aumento de renda da população. 


\section{REFERÊNCIAS}

BARRETO, L. P. Educação para o empreendedorismo. Educação Brasileira, 20(41), p. 189-197, 1998.

BAGGIO, A. F.; BAGGIO, D. K. Empreendedorismo: Conceitos e Definições. Rev. de Empreendedorismo, Inovação e Tecnologia, 1(1): 25-38, 2014 - ISSN 2359-3539, 2014.

BRITO, A. M.; PEREIRA, P. S.; LINARD, A. P. Empreendedorismo. Juazeiro do Norte: Instituto Federal de Educação, Ciência e Tecnologia do Ceará - IFCE, 2013.

CASTRO, C. M. A prática da pesquisa. São Paulo, McGraw-Hill do Brasil, 1977.

CERVO, A., BERVIAN, P., SILVA, R. Metodologia científica. (6ª ed.). São Paulo: Pearson Prentice Hall. 2007.

DOLABELA, F. A corda e o sonho. In: Revista HSM Management, 80, p. 128-132, 2010.

DORNELAS, J. C. Empreendedorismo: transformando ideias em negócios. Rio de Janeiro: Elsevier, 2008.

GIL, A. C. Métodos e técnicas de pesquisa social. 5. ed. São Paulo: Atlas, 1999.

HISRICH, R. D. E PETERS, M. P. Empreendedorismo. Porto Alegre: Bookman, 2004.

IBQP (Instituto Brasileiro da Qualidade e Produtividade); SEBRAE (Serviço Brasileiro de Apoio às Micro e Pequenas Empresas); UFPR (Universidade Federal do Paraná). GEM - Global Entrepreneurship Monitor. Relatório Executivo 2018, Empreendedorismo no Brasil. Disponível em: https://datasebrae.com.br/wpcontent/uploads/2019/02/Relat\%C3\%B3rio-Executivo-Brasil-2018-v3-web.pdf. Acesso em: 29.10.2019.

LAKATOS, E. M.; MARCONI, M. A. Fundamentos metodologia científica. 4.ed. São Paulo: Atlas, 2001.

LONGENECKER, J. G.; MOORE, C. W.; PETTY,J.W. Administração de pequenas empresas: ênfase na gerência empresarial. São Paulo: Pearson, 2004.

PINTO, E. P. Organizador. Gestão empresarial: casos e conceitos de evolução organizacional. São Paulo: Saraiva, 2007.

SCHUMPETER, J. A. A teoria do desenvolvimento econômico. São Paulo, Nova Cultura, 1988.

SEBRAE. Disciplina de empreendedorismo. São Paulo: Manual do aluno, 2007.

TRIVIÑOS, A. N. S. Introdução à pesquisa em ciências sociais: a pesquisa qualitativa em educação. São Paulo: Atlas, 1987.

VERGARA, S. C. Projetos e relatórios de pesquisa em administração. 10ª Ed. São Paulo: Atlas, 2009.

ZANELLA, L. C. H. Metodologia de pesquisa. Florianópolis: Departamento de Ciências da Administração/UFSC, 2007. 